Scientiæ studia, São Paulo, v. 11, n. 3, p. 667-70, 2013

\title{
ฟै? \\ Las lecciones de sociología de Auguste Comte
}

\author{
Tonatiuh Useghe Sandoval
}

\section{Física social}

Auguste Comte

Estudio preliminar y traducción: J. R. G. Falque

Akal

Madrid, 2012, 1.295 págs.

Al redactar el Curso de filosofía positiva, Comte se propuso dos metas: sistematizar el conjunto del saber y fundar la ciencia social. De las seis ciencias que componen la escala enciclopédica, las cinco primeras (matemática, astronomía, física, química, biología) estaban ya constituidas, razón por la cual bastaba con poner en relieve sus principales resultados. Pero tal no era el caso de la última, la sociología, razón por la cual ocupa por sí sola tanto espacio como las otras juntas, es decir, tres de los seis tomos del Curso. Dos de las lecciones de sociología habían ya sido traducidas al español por Pavón, pero es la primera vez que se dispone de una traducción de todas (de la 46 a la 57). Las lecciones $5^{8}$ a $60-$ a pesar de su importancia capital, dado que permiten hacer la transición entre el Curso y el Sistema de política positiva - no figuran en la selección, puesto que no tratan ya de sociología, sino que recopilan el conjunto del Curso y exponen las conclusiones generales.

Bajo el título "La parte dogmática de la filosofía social", el primero de los tres tomos dedicados a la sociología abarca las lecciones 46 a $5^{1}$, sin duda las más interesantes para el lector de nuestros días, pues, tras unas "consideraciones políticas preliminares sobre la necesidad y oportunidad de la física social" (lección 46), Comte recapitula las principales tentativas para fundar la ciencia social, desde Aristóteles hasta Condorcet, sin olvidar a los economistas (lección 47). Vienen luego unas consideraciones sobre el método utilizado por la sociología (lección 48), sobre su posición dentro del sistema de las ciencias y, en particular, sus relaciones con la biología (lección 49), sigue después un esbozo de la estática social (lección 5 o) y de la dinámica social (lección 51), que retoma de manera más detallada la ley de los tres estadios, ya expuesta en la primera lección del Curso. 
La segunda parte, la parte histórica de la filosofía social, posee el mismo número de lecciones, pero es dos veces más larga (ocupa dos de los tres tomos y aquí las páginas 475 a 1.170). Conforme se va avanzando, las lecciones se van volviendo cada vez más extensas, hasta convertirse en verdaderos libros (la 56 cuenta con $15 \circ$ páginas y la 57 con 170). Están consagradas respectivamente a las tres variantes del pensamiento teológico: el fetichismo (lección 52), el politeísmo, esencialmente griego y romano, que se presenta como la edad de oro de la teología, y el monoteísmo, tal como se desarrolló en la Edad Media y que el positivismo interpreta como una autodestrucción de la teología carcomida desde adentro por la metafísica. Con la escolástica, en efecto, la filosofía no es la esclava de la teología, sino todo lo contrario (p. 755-76). Aparecen luego los tiempos modernos que, según Comte, inician en el siglo catorce y en los cuales se distingue un movimiento de descomposición del pensamiento teológico-metafísico (lección 55) y un movimiento de formación del espíritu positivo (lección 56). La lección 57 empieza estudiando la "gran crisis", es decir, la revolución francesa que se había preparado durante el siglo dieciocho y que todavía faltaba por terminar en 1842, época en la que Comte acababa de redactar su tratado, y concluye después las lecciones de sociología retomando la problemática política de la lección 46. La ciencia social es, en efecto, para el arte político, lo que la ciencia biológica es para el arte médico. Asistimos, entonces, a una de las presentaciones más completas de la concepción positiva del poder espiritual (p. 1101-6o).

De nuestros días, la filosofía de la historia, ya sea hegeliana, marxista o positivista, es percibida como un producto histórico, típico del siglo diecinueve, y la dinámica social o teoría del progreso, la cual, junto con la estática o la teoría del orden, conforma las dos partes de la sociología, nos parece de una positividad insuficiente. Por ende, es indiscutible que el marco teórico ha resistido mal al paso de los años, sin embargo quien se tome la pena de seguir a Comte en sus análisis se verá recompensado. En una época en la que el pensamiento político estaba focalizado en torno a las nociones de estado y en la que el nacionalismo tomaba auge, Comte se interesa, por el contrario, a las relaciones internacionales. Se trata de un europeo convencido, ya que, como lo explica el comienzo de la lección 52, la historia europea es la única serie plenamente documentada (p. 476). El estudio de la humanidad, objeto de la sociología, se reduce así al estudio de Europa. Acusarlo, sin embargo, de europeo-centrismo sería una conclusión precipitada, ya que fue uno de los pocos que en su tiempo criticó la colonización, llegando a anhelar públicamente que Argelia fuera devuelta a los argelinos. Las lecciones de historia contienen abundantes análisis de una gran agudeza: sobre el teatro español comparado con el teatro isabelino (p. 934- 7 ), sobre la oposición entre el modelo francés y el modelo inglés en la construcción europea, o también so- 
bre la distinción entre la filosofía natural y la filosofía moral como clave para interpretar la historia del pensamiento occidental (p. 946, 1.088).

Es cierto que la posición que ocupa la sociología en el Curso difiere mucho de su situación actual, pues aparece después de la biología, con la cual comparte su interés por los seres organizados. Pero, sobre todo, es la ciencia final, la que resume todas las demás y a la que, por esa razón, se le otorga la presidencia de la escala enciclopédica. De allí un estatuto ambivalente. Es una ciencia como las otras, la ciencia de los hechos sociales, como la biología es la ciencia de los hechos biológicos, pero es también la reina de la ciencias, la que recapitula todas las demás. De allí que a partir de entonces Comte concluya que el único punto de vista filosófico es el punto de vista sociológico.

Las lecciones están precedidas por una larga introducción que ayudará a que el lector las sitúe en la obra de Comte. "Mi vida es una novela", observaba éste. Falque, en su estudio preliminar, presenta la carrera de Comte, partiendo de los escritos de juventud, marcados por su formación en la Escuela Politécnica y su amistad con San Simón, que aún hoy constituyen una lectura obligatoria para quien quiera comprender la meta que el autor del Curso aspiró toda su vida alcanzar, y desembocando en el Sistema de política positiva y las últimas obras, donde el fundador de la religión de la humanidad exploró caminos que muchos de sus primeros discípulos se negaron a seguir. Falque añadió también al volumen una bibliografía, notas explicativas, un índice que facilitará seguramente la consulta, y la tabla de materias de los seis tomos del Curso, lo que permite darse cuenta de la variedad y amplitud de los temas abordados.

Es una lástima que las páginas del volumen no dispongan de un encabezado precisando el título de la lección abordada, ya que le permitirían al lector situarse mejor en el texto: en una obra tan larga, es siempre útil saber de entrada en qué lección se encuentra uno. Igualmente, el título Física social es un poco engañoso, puesto que le da a creer al lector poco familiarizado con la obra del filósofo que Comte escribió un libro así titulado. Error que corre el riesgo de propagarse cuando se cite la traducción. Hubiera bastado con precisar de manera explícita, en la portada, que se trata de las lecciones de sociología del Curso de filosofía positiva, lo cual no excluye mantener "Física social" como un subtítulo, plenamente justificado por cierto.

Este volumen será sin duda muy valioso. Permitirá que los sociólogos retomen posesión de una parte de su historia pero también será rico en enseñanzas para los filósofos. En efecto, no hay que perder de vista que después de 1789, la gran veta de la filosofía política clásica estaba agotada. De allí la ausencia de nombres ilustres en dicho dominio, salvo Hegel, excepción que confirma la regla. 
Tonatiuh Useghe Sandoval Escuela Doctoral del Departamento de Filosofía, Universidad de Paris 1, Francia. tonatusco@yahoo.fr

The lessons of sociology of Auguste Comte

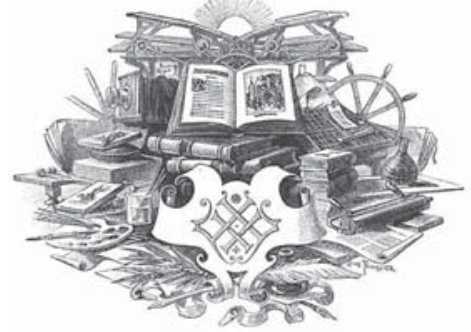

